\title{
A "TRANSINDIVIDUALIDADE" SPINOZISTA: ENTRE A DETERMINAÇÃO E A EXPRESSÃO
}

\author{
Mariana de Gainza \\ PPGFil - Universidade de São Paulo
}

\begin{abstract}
In this article, we seek to rebuild a complex concept of individual, using the tension between two Spinoza's interpretative currents, usually considered as incompatible (the one that, continuing the Hegelian tradition, puts the emphasis on determination, and the other one that, from Deleuze, underlines the notion of expression). While understanding the individualities as expressive determinations or determinate expressions of the production processes and the concrete relations in which they are constituted, we're approaching to the concept of "transindividuality", just as it's actually recovered by E. Balibar.
\end{abstract}

Keywords: individual, modes, parts, determination, limit.

Resumo:Neste artigo procuramos reconstruir um conceito complexo de indivíduo, valendonos da tensão entre duas correntes interpretativas do spinozismo habitualmente consideradas incompatíveis entre si (aquela que, prosseguindo a tradição hegeliana, coloca a ênfase na determinação, e aquela outra que, a partir de Deleuze, sublinha a noção de expressão). Compreendendo as individualidades como determinações expressivas ou expressões determinadas dos processos de produção e das relações concretas nas quais elas se constituem, nos aproximamos da noção de "transindividualidade", tal como atualmente é recuperada por $\mathrm{E}$. Balibar.

Palavras-chave: indivíduo, modos, partes, determinação, limite.

Entre diversas perspectivas teóricas é possível identificar, às vezes, certas "afinidades eletivas" ou ressonâncias conceituais, um apelo recíproco que permite que os âmbitos de suas formulações se conectem, de tal maneira 
que as noções que estão em jogo em cada uma delas "cresçam", ganhem em profundidade ao ser iluminadas por outras filosofias. Afinidades eletivas desta índole foram assinaladas e investigadas por Etienne Balibar em relação às obras de Spinoza e Simondon; concretamente, o conceito simondoniano de "transindividualidade" se mostrou produtivo na hora de ensaiar uma atualização da ontologia spinozana com vistas à reelaboração contemporânea dos fundamentos das ciências humanas e sociais. Minha tentativa neste texto é de procurar, num spinozismo tensionado por duas linhas de interpretação geralmente apresentadas como opostas e incompatíveis, certos espaços conceituais que se abrem na direção de dito diálogo com as formulações simondonianas.

Se a infinitamente diversificada atividade produtiva em que consiste a substância única concebida por Spinoza pode ser lida nos termos do processo de individuação em que pensa Simondon, cabe a pergunta sobre os conceitos que podem servir-nos para precisar o sentido desse processo. $\mathrm{O}$ processo de diferenciação imanente a uma infinita potência de produção pode ser considerado - e aqui intervêm duas tradições divergentes de leitura do spinozismo - como um processo de determinação que se realiza mediante negações progressivas ${ }^{1}$, ou como um processo de expressão que se efetua através de distinções positivas ${ }^{2}$. Ora bem, quando o comentário escolhe

1 Enquanto a ontologia spinozana coloca, em primeiro lugar, a existência de uma única substância absolutamente infinita, toda uma tradição de leituras fez da questão relativa à insuficiente fundamentação do ser das coisas finitas o eixo da crítica ao spinozismo. Hegel, para quem só é possível dar conta do concreto através da negação que vai efetivando uma determinação progressiva do ser, celebrou uma frase spinozana extraída de uma carta a Jarig Jelles: "Determinatio negatio est". E graças à geralização de uma asserção que se referia estritamente à concepção da figura como a determinação externa de um corpo, reconheceu Spinoza como um dialético quase consumado por ter sabido compreender o princípio fundamental que presidiria a constituição de qualquer existência: toda determinação é uma negação. Só que no spinozismo, segundo Hegel, toda determinação é uma negação e tão somente uma negação, frente à substância como a única e absoluta positividade existente, afirmação de uma essência infinita. O negativo é o oposto do positivo, e não pode conciliar-se com ele, de maneira que a negação spinozana revela-se abstrata e exterior; e a realidade que determina, excluída do substancial, está por isso condenada a desaparecer. O diagnóstico hegeliano é que a determinação como simples negação não pode dar conta do ser essencial do individual. Esse objetivo só será atingido pela "absoluta determinabilidade ou negatividade, que é a forma absoluta (...), negação da negação e, portanto, uma verdadeira afirmação" (HEGEL, G.W.F., Lecciones sobre la historia de la filosofía III. México: Fondo de Cultura Económica, p. 307).

${ }^{2}$ A expressão, segundo DELEUZE, concerne diretamente à indagação sobre a natureza do infinito positivo spinozano; isto é: a expressão é o que determina a relação entre a substância absolutamente infinita e a infinidade de atributos que constituem sua essência infinita. A relação entre a substância que se exprime, os atributos que são suas expressões e a essência exprimida por eles se compreende 
transitar, de maneira excludente, um destes caminhos interpretativos, se produz às vezes uma estabilização definitiva da argumentação, e o resultado (de certa maneira, acabado) do que requeria ser pensado como um processo (sempre aberto) de individuação se resume, então, em duas versões antitéticas: ou bem as coisas finitas - quer dizer, os indivíduos - desaparecem, pois todas as determinações, negando-as umas às outras, acabam por consagrar uma generalizada destruição; ou bem as coisas finitas, como expressões puramente positivas de uma potência infinita, assumem-se como indivíduos plenos ganhando assim uma substancialidade tal, que acaba confundindo-se com a que, em princípio, só a "Deus" pertencia. Estas "conseqüências", entretanto, não se correspondem com o verdadeiro conceito dos "modos" da substância spinozana, enquanto efeitos imanentes a uma natureza concebida como produtividade. $^{3}$

enquanto a essência se distingue da substância pelos atributos, a substância se distingue dos atributos pela essência, e os atributos se distinguem da essência pela substância. $O$ absolutamente infinito se exprime, então, distinguindo-se. E ao fazê-lo, produz outras tantas expressões distintas, os infinitos modos existentes, de forma que é também a expressão produtiva dessa potência diversamente qualificada que explica a existência dos modos singulares. A expressão e a distinção seriam, então, as chaves conceituais do processo de diferenciação imanente que explica a constituição múltipla e multiforme da realidade. (Cf. DELEUZE, G., Spinoza et le problème de l'expression. Paris: Minuit, 1968).

${ }^{3}$ A estratégia de leitura do spinozismo da tradição hegeliana consiste em opor a perspectiva da substância e a dos modos, "interrompendo", por dizê-lo assim, a fluidez da construção spinozana num de seus "momentos": enquanto a substância é o que é em si, os modos são o que é em outro; se a substância é eterna, os modos duram; enquanto a substância é infinita e indivisível, os modos se concebem determinados e compostos de partes. Mas se ao caracterizar os modos nos restringirmos a essa série de notas distintivas, conservando unicamente 0 aspecto "opositivo" ou excludente em relação à causa sui, subestimaríamos as conseqüências fundamentais da associação entre o caráter imanente da casualidade substancial e a determinação básica da essência da substância como sendo a infinita produtividade de uma potência infinita. Nesse sentido, as leituras que se fizeram do spinozismo nos termos de uma ontologia positiva da potência (na linha de Nietzsche e Deleuze) representam um importante corretivo dessa tendência a opor as perspectivas da substância e dos modos. A ênfase, neste caso, recai em que "as coisas particulares nada são senão afeç̧ões dos atributos de Deus, ou seja, modos, pelos quais os atributos de Deus se exprimem de maneira certa e determinada" (E,I, P25,cor.), pelo qual o "ser em outro" é positivamente (e não opositivamente) expressão parcial (certa e determinada) da potência absoluta e ao mesmo tempo qualificada (através de um atributo) de uma força de produção absoluta (a causa de si, que tem a potência de produzir tudo o que existe ao auto-produzirse). E dado que "a potência de Deus é sua essência mesma" (E,I,P34), essa potência é a que define as essências das coisas singulares que, enquanto efeitos de uma causa imanente, são expressões determinadas dessa potência (ou o que é o mesmo neste caso: partes constituintes dessa potência, ou seus infinitos graus) e, por isso, elas mesmas são causas de seus próprios efeitos. Entretanto, em algumas versões desta tradição "expressivista", o que acaba acontecendo é que o que antes era lido como oposição, passa a ler-se como simples identidade, de tal forma que os modos spinozanos se interpretam como expressão imediata do absoluto; do que segue que os aspectos fundamentais da determinação, a limitação e a precariedade associada à finitude tendem a perder relevância. Por isso, 
Como pensar os modos spinozanos, se assumirmos que eles constituem o conceito do individual de uma maneira complexa e afastada de qualquer perspectiva reducionista? Como escapar dessa alternativa entre a expressão (do lado da distinção e a afirmação) e a determinação (do lado da negação) ${ }^{4}$, e nos aproximar de uma compreensão das individualidades como determinações expressivas, ou expressões determinadas dos processos de produção e das relações concretas nas quais tais individualidades são e em virtude das quais se constituem?

Neste texto, utilizaremos o exemplo spinozano dos círculos não concêntricos da conhecida Carta 12 "sobre o infinito" para tematizar a singular concepção spinozana da determinação e do limite. Se, nos termos da Carta 12, o que "se chama indefinido" deve ser diferenciado tanto daquilo que é infinito por sua essência quanto do que é infinito por sua causa (quer dizer, deve distinguir-se tanto da substância e seus atributos - infinitos por sua essência - quanto dos modos infinitos - que devem sua infinidade à causa de que seguem), é claro que o que Spinoza quer ilustrar com este exemplo se refere ao ser do que é finito ou limitado - que, entretanto, ao ser em outro, envolve, em sua própria definição, esse outro (infinito) no qual é. Da natureza "indefinida" da existência das coisas finitas e limitadas é do que trata o exemplo, quer dizer, da determinação positiva das coisas finitas enquanto durações singulares. E dado que a existência de uma coisa finita, quando é adequadamente concebida, coincide com a própria essência dessa coisa (isto é, com o esforço variável mas contínuo pelo qual ela persevera na existência, ou seja, dura), podemos dizer que o exemplo ilustra a forma em que deve se conceber, evitando a abstração, o ser dos entes finitos, na inseparabilidade de sua essência e sua existência; isto é, o modo em que o infinito é efetivamente imanente ao finito. Ou dito com outras palavras: o exemplo nos deixa entrever uma concepção do ser do individual como efeito imanente de um processo de individuação. Sustentaremos, assim, que se o que está em jogo na ilustração geométrica é a determinação positiva da

resulta imprescindível, conforme acreditamos, que se mantenha a tensão crítica entre as aproximações "dialéticas" e as leituras "positivas" do spinozismo.

${ }^{4}$ Alternativa que encontramos formulada de maneira explícita, por exemplo, em Deleuze, quando diz: "A teoria spinozista da negação (sua eliminação radical, seu estatuto de abstração e de ficção) apóia-se na diferença entre a distinção, sempre positiva, e a determinação negativa: toda determinação é negação". (DELEUZE, G., Spinoza: Filosofía Práctica. Barcelona: Tusquets, 2001, p. 110). 
realidade do finito, essa "determinação" deve ser contrastada com a determinatio negatio da Carta 50 a Jarig Jelles, apresentada por Hegel como a exclusiva concepção spinozista da determinação. Por fim, à compreensão transfigurada do que sejam as "partes" componentes de um "todo" que se desprende do exemplo geométrico, adicionaremos as sugestões que surgem da Carta 32 a Oldenburg. Supomos que este itinerário pode nos ajudar a restituir - frente às mencionadas leituras unilaterais - a complexidade que a perspectiva spinozista requer para dialogar com maneiras atuais e não reducionistas de conceber a individualidade.

\section{O limite (ou a determinação positiva das coisas finitas)}

Na Carta 12 a Meyer, para ilustrar a noção de algo limitado que, entretanto, compreende uma infinidade que, por sua vez, não pode ser numericamente determinada, Spinoza fornece o famoso exemplo dos dois círculos não concêntricos:

Todas as desigualdades do espaço $\mathrm{AB}$ e $\mathrm{CD}$ interposto entre dois círculos não concêntricos e todas as variações que deve sofrer a matéria que nele se move superam todo número. Não é da excessiva magnitude do espaço interposto que isso é concluído, pois, por menor que seja a porção dele que tomemos, as desigualdades dessa pequena porção ainda superarão qualquer número. Nem essa conclusão é obtida porque, como em outros casos, não conhecemos um máximo e um mínimo, pois em nosso exemplo conhecemos ambos, o máximo sendo $\mathrm{AB}$ e o mínimo, $\mathrm{CD}$. Nossa conclusão é obtida porque à natureza do espaço interposto entre dois círculos não concêntricos não pode ser aplicado o número. ${ }^{5}$

É por sua natureza própria, então, que o espaço interposto entre dois círculos não concêntricos e de diâmetros diferentes, o menor inscrito no maior, inclusive sendo um espaço limitado (isto é, tendo um máximo e um mínimo), não é numericamente determinável, pois as desigualdades das distâncias contidas nesse espaço e as variações do movimento que deveria

${ }^{5}$ Spinoza, "Correspondência", em Os pensadores, São Paulo, Abril Cultural, 1979, p. 383. 
sofrer a matéria que se movesse em dito espaço superam todo número. Mas o que quero ressaltar aqui e considerar em detalhe (mais do que a inadequação do número para conceber tanto o infinito quanto o finito, que é o tema da carta), é que graças à suposição de que os círculos não coincidem em seu centro, as "partes" que constituem essa certa "interioridade" delimitada não são partes discretas, mas partes diferenciais (desigualdades ou relações entre distâncias, ou seja, passagens); que, por isso, não havendo entre elas descontinuidade mas uma variação continua, o que acontece ao interior desse espaço finito deve ser concebido em termos de movimento; e que, correlativamente, há outra noção de limite em jogo, que não é aquele limite que a circunscrição fixa de um espaço estabelece.

Precisemos isso melhor. Como muitos intérpretes da obra spinozana tem enfatizado ${ }^{6}$, não se trata da impossibilidade de atribuir um número ao conjunto (infinito) das distâncias desiguais compreendidas entre os dois círculos, mas sim - o que em princípio não pareceria mais do que uma sutil diferença na enunciação - da impossibilidade de numerar as desigualdades do espaço interposto. Essa pequena distinção é, entretanto, substantiva. Pois as "distâncias desiguais" se identificam diretamente com os infinitos segmentos desiguais que podem ser traçados entre os dois círculos, enquanto que, pelo contrário, as "desigualdades do espaço" interposto são as desigualdades entre essas distâncias desiguais, quer dizer, as diferenças entre esses infinitos segmentos desiguais. No primeiro caso, as partes, identificadas com os segmentos, podem ser positivamente assinaladas; no segundo caso, cada "parte" é uma diferença entre dois segmentos, a diferença entre as distâncias que cada um desses segmentos assinala positivamente. E porque cada "parte" é, em si mesma, uma passagem, o exemplo fala justamente do movimento da matéria que tem que circular nesse espaço. Assim, as desigualdades do espaço compreendido entre dois círculos não concêntricos constituem o conjunto não numerável das diferenças entre suas distâncias desiguais ou, o que é o mesmo, a variação sem fim constituída por uma infinidade de passagens ou transições.

\footnotetext{
${ }^{6}$ Remito em particular a Gueroult, Deleuze e Macherey.
} 
Mas o que é fundamental ressaltar é que a noção de limite presente no exemplo da Carta 12 não é a mesma que aparece naquela outra carta famosa (que Hegel contribuiu a popularizar) ${ }^{7}$, a carta 50 a Jarig Jelles:

No que concerne ao problema da figura, digo que não é algo positivo, mas uma negação. É manifesto que a matéria em sua integridade não pode ter figura e deve ser considerada indefinida, a figura só existindo nos corpos finitos ou determinados. Com efeito, quem diz que percebe uma figura indica somente que concebe uma coisa determinada e de que maneira ela o é. Esta determinação, portanto, não pertence ao ser da coisa, mas indica o seu não ser. Portanto, a figura é apenas a determinação e a determinação é negação e, assim, ela não pode ser algo, mas só uma negação. ${ }^{8}$

A figura não é, então, algo positivo, mas o não-ser da coisa que delimita, pois graças à figura se realiza a determinação de um conteúdo, sim, mas da perspectiva de um outro que o circunscreve pondo-lhe um término espacial. A determinação é negação neste sentido preciso, e a determinação enquanto negação constitui um limite necessariamente conectado com nossa percepção dos corpos finitos ("pois quem diz que percebe uma figura, não indica outra coisa senão que concebe uma coisa determinada e como está determinada", embora "esta determinação não pertença à coisa segundo seu ser”). Isto não quer dizer, certamente, que a determinação nesta acepção refira a algo puramente subjetivo, pois a figura se associa às coisas que realmente são "finitas ou determinadas". A abstração implícita na consideração de uma coisa unicamente segundo seu não-ser, e não segundo seu ser, é uma operação objetiva que não se relaciona com uma "distorção" do olhar ou tão somente com os limites de nossas capacidades perceptivas, mas se sustenta na efetiva delimitação externa entre os corpos existentes ${ }^{9}$. Mas embora não se trate de

\footnotetext{
${ }^{7}$ Neste sentido, a forma em que HEGEL interpretou a determinação spinozana, não pode dissociar-se da forma equivocada em que leu o exemplo geométrico da Carta 12, justamente nos termos de uma somatória infinita de "distâncias desiguais".

${ }^{8}$ SPINOZA, "Correspondência", op.cit., pp. 398-399.

${ }^{9}$ Neste sentido, há uma necessária relação entre esse ser finito ou limitado das coisas, e os limites inerentes a nossa própria percepção - ela também finita. Assim, também é a noção de limite que nos permite explicar a operação abstrativa: além de certo limite, com efeito, não podemos imaginar
} 
uma falsa percepção, constitui em qualquer caso uma consideração unilateral das coisas. Não toda determinação é uma negação (que nos permite considerar a coisa segundo seu "não-ser"), pois a determinação também é afirmação (que nos permite considerar a coisa segundo seu "ser").

O exemplo geométrico da Carta 12 serve então para que consideremos - frente à noção da figura que implica a idéia da determinação como negação - a outra cara da determinação, enquanto afirmação. E se a Carta 12 nos incita a pensar de outra forma a determinação, isso é assim porque o que Spinoza trata lá de maneira diferente é a noção de limite. A determinação como negação da Carta 50 constitui a idéia de limite não só como determinação externa, mas também como idéia ou ser de razão, e é nesse sentido que equivale a conceber uma coisa segundo seu não-ser. Mas acontece que se nos restringíssemos a esta noção de limite - como Hegel faz, ao generalizar e estender o que é válido para a figura à determinação ontológica de todos os seres finitos -, seria lícito dizer que, em última instância, o finito na filosofia spinozana não tem nenhuma realidade: os limites não são reais, mas meros entes de razão e, por isso, não são nada que realmente exista na natureza. E se o limite nada é, o que supomos limitado, quer dizer, finito, tampouco é nada: a única realidade é, desta maneira, a substância absolutamente infinita, que não permite pensar em seu interior nenhuma determinação, pois toda determinação não é mais que algo imaginário e subjetivo, que se dissolve assim que nos situamos na perspectiva verdadeira da substância eterna. Se o limite é considerado como uma não-realidade que separa abstratamente o que, concebido adequadamente, é estritamente positivo, isso significa que o único horizonte verdadeiro é a absoluta concordância do todo, não sendo as partes mais do que "partes totais" que simplesmente afirmam a positividade desse todo, sem opor-se nem negar-se realmente entre si: a oposição, a negação, o limite, são unicamente um produto da mente humana que imagina confrontações onde só há uma perfeita harmonia.

Frente a esta leitura não é suficiente enfatizar que a determinação externa é real e efetiva. Pois, como sabemos, se poderá retrucar - fazendo uso de outro lugar comum da crítica ao spinozismo - que o determinismo 
universal é o reverso necessário da subsistência única de Deus como única natureza necessária: todas as coisas se eliminam, em virtude de uma causalidade mecânica, atuando umas contra as outras. Essa constatação "naturalista" (o peixe maior come o menor, e é por sua vez devorado por outro maior) tampouco outorga à alteridade e aos limites efetivamente existentes uma entidade real, que é precisamente aquilo que a problemática da transindividualidade quer colocar Pois a única coisa que a dissolução universal e transitiva de todos os seres finitos consagra é a absoluta unidade da natureza, para cuja positividade plena é indiferente que esta ou aquela determinação finita pereça deste ou aquele modo, visto que o destino fatal de todas é esse perecer. A totalidade assim concebida, apesar dessa efetividade que lhe reconhecemos à determinação externa, é, em definitivo, o complemento exato daquela positividade substancial reconhecida numa primeira instância, pois consiste na coexistência conjunta meramente constatada de uma infinidade de seres finitos que aparecem e desaparecem de forma permanente, sem verdadeiro conflito (onde a natureza total se afirma conservando uma mesma proporção de movimento e repouso - nessa sucessão perpétua dos seres).

Não é suficiente, dissemos então, insistir na realidade da determinação externa do finito, mas é preciso que a noção de limite seja reconsiderada. Por isso, o exemplo geométrico da Carta 12 deve ser lido em relação a essa emenda da disposição imediata a conceber o limite só como uma determinação externa e às coisas reais como se fossem figuras: o que está implícito no caso dos dois círculos não concêntricos é outra concepção do limite, que lhe restitui sua realidade, e o associa à própria consistência positiva e ao ser relacional dos seres finitos. É nessa direção que se dirige, ao nosso entender, a riqueza do conceito de transindividualidade.

Se quisermos encontrar no exemplo o limite como negação tal como se descreve na Carta 50, temos que prestar atenção à delimitação desse espaço pelas circunferências do círculo maior e o círculo menor. Nesse sentido, esse espaço está perfeitamente delimitado e são as circunferências que fazem dele isso que existe entre outras coisas ou corpos que o determinam externamente; por isso, as circunferências são o "não-ser" do espaço interposto, tanto no sentido de que, para além delas, ele deixa de ser esse espaço, como no sentido de que ele próprio, enquanto é esse espaço, quer dizer, segundo seu "ser", não é uma circunferência. 
O que é, então, esse espaço interposto entre os dois círculos? É um espaço definido, ou seja, limitado dentro de si ao levar em si a finitude de sua definição, que por fazer dele o que é, exclui também o que ele não é ${ }^{10}$. A não concentricidade dos círculos (derivada da relação específica que liga as circunferências) é a que define de certa e determinada maneira a constituição singular desse conteúdo espacial diferente de outros, ao qual incumbe um "máximo" e um "mínimo" que lhe são próprios: lhe pertencem, no sentido preciso em que constituem esse conteúdo, compartilhando a mesma natureza que o resto de seus componentes (são diferenças entre distâncias, assim como todas as outras "partes"). Por isso, estão necessariamente imbricados com as outras relações diferenciais que compõem esse espaço, e, por isso, o limite assim concebido não é separável do "corpo" da coisa: é interno. É por isso também que, para além do limite, a existência da coisa continua: a matéria que se move no interior do espaço interposto, aumenta ao máximo e diminui ao mínimo sua velocidade quando atravessa as partes limites em que a distância diferencial é a menor ou a maior; mas depois de aumentar ao máximo e de diminuir ao mínimo, o movimento prossegue ao interior do mesmo espaço. A matéria móvel que constitui a "interioridade" concreta desse espaço se define, desta maneira, pela proporção variável de movimento e de repouso em que consiste sua existência ${ }^{11}$.

É por este conjunto de rasgos que, conforme dissemos, o exemplo geométrico da Carta 12 era convocado para ilustrar a existência das coisas finitas, em sua coincidência com a essência dessas mesmas coisas. A existência

\footnotetext{
10 Parafraseio palavras de ALTHUSSER, no prefácio de Lire Le Capital.

11 Deleuze nos oferece uma metáfora esclarecedora para compreender melhor esta diferença que enfatizamos entre a determinação como delimitação externa de algo que, mediante a negação, estabelece o que esse algo não é (e que explica que as coisas singulares sejam "modos finitos"), e esse outro limite que atua como uma determinação interna ou auto-determinação, que exprime o que a coisa é (e que explica, assim, que as coisas singulares sejam "modos finitos"). O limite de uma coisa que exprime o que ela essencialmente é coincide, diz DELEUZE, com a extensão de sua ação, de igual maneira que um bosque se estende até suas margens, lá onde começa a pradaria; sendo tão impossível definir esse limite como uma figura que circunscreve o território de maneira fixa, quanto é impossível supor que a pradaria determina externamente 0 bosque definindo seus contornos. 0 bosque é 0 resultado de sua própria potência expansiva, e seu término está aonde sua ação se detém, e onde sua existência se mescla com a existência da pradaria. (Aula de Deleuze sobre Spinoza do dia 17/2/1981). A essência de qualquer coisa finita é, então, como a do bosque, a afirmação de uma potência de atuar que se estende tanto quanto a natureza atualmente determinada da coisa o permite; e, por isso, o limite deixa de ser algo abstrato e estático, e recupera o dinamismo requerido por uma consideração realista das coisas.
} 
de algo, que pode ser abstratamente determinada ad libitum ${ }^{12}$, não admite, porém, tal determinação, se é considerada segundo sua natureza: deve ser vista, enquanto efeito necessário da causa que a produz, como uma continuação indefinida na existência. Enquanto a existência finita é no infinito, da potência dessa causa infinita provém a própria força de perseverar na existência que faz da existência das coisas particulares, essencialmente, uma existência contínua ou indefinida. A reversibilidade entre essência e existência característica do spinozismo (que pertence em princípio, com pleno direito, só à causa sui) se comprova aqui no caso das coisas finitas: a essência se define como potência ou esforço ("que não envolve um tempo finito, mas indefinido") por perseverar na existência; a existência é a duração contínua que resulta ou coincide com a afirmação dessa essência como esforço de perseverança. Desta maneira, o exemplo geométrico ilustra a forma em que a existência de uma coisa limitada coincide com o ser atual de uma essência, consistindo esta no esforço variável mas contínuo para permanecer durando, ou seja, existindo. A matéria, no exemplo, continua indefinidamente seu movimento, atravessando os infinitos estados que fazem ela ser o que é, numa existência infinitamente variável que, entretanto, encontra-se compreendida dentro de certos limiares de extensão que definem sua natureza (um máximo e um mínimo), associados por sua vez ao que esse espaço material é em virtude da determinação externa de seus limites.

\section{As partes (ou a modulação infinita da natureza)}

Mas dissemos que, para aproximar a ontologia de Spinoza ao conceito de transindividualidade, tão importante como a reconsideração do limite é a modificação da idéia de "parte” que o exemplo implica. Detenhamo-nos nisto mais um instante. Uma parte é uma relação e, nesse sentido, está de maneira iniludível ligada com as outras partes e com o todo que compõe, pois o que se define relacionalmente não admite ser considerado como

\footnotetext{
12 É o que diz SPINOZA na Carta 12 a propósito da existência dos modos, que pode ser considerada maior ou menor, ou dividida em partes, sem destruir seu conceito. Correlativamente, o exemplo geométrico oferece similares possibilidades de determinação: "Em todo o espaço compreendido entre dois círculos que têm centros distintos, concebemos uma multidão de partes duas vezes maior que em sua metade, e, no entanto, o número de partes, tanto da metade quanto de todo o espaço, é superior a qualquer número atribuível" (Carta 81 de Spinoza a Tschirnhaus).
} 
fechado dentro de si, auto-suficiente ou independente. As coisas se consideram como partes de algum todo - diz Spinoza na Carta 32 a Oldenburg - enquanto estão em mútua conexão (coherentia), quer dizer, enquanto se ajustam realmente umas às outras e concordam entre si na medida do possível (as leis ou a natureza de uma parte adaptando-se às da outra, de tal maneira que não existe a mínima contrariedade entre elas). "Por exemplo, quando os movimentos das partículas de linfa, de quilo, etc., levando em conta seu tamanho e sua figura, ajustam-se uns aos outros de sorte que concordem plenamente entre si e que todos juntos constituam um só fluido, então, e só então, o quilo, a linfa, etc., são considerados como partes do sangue"13. Assim, os movimentos das partículas que se ajustam perfeitamente entre si são os que consideramos, no exemplo geométrico, como as "passagens" que, articuladas, constituíam todas juntas um só fluido ou movimento contínuo; "levando em conta o tamanho e a figura" de cada partícula, pois, como também dissemos, a determinação externa que explicava a existência da coisa como uma coisa entre coisas fazia de sua consistência interna um certo movimento de determinadas características. "Os corpos se distinguem um do outro em razão do movimento e do repouso, da rapidez e lentidão, e não em razão da substância"14, e quando estão conectados e se comunicam uns aos outros seus movimentos segundo uma certa relação, compõem um único corpo ou "um indivíduo que se distingue de outros por essa união de corpos"15. A união de corpos que se caracteriza por certa relação de movimento e repouso, em virtude da qual se comunicam entre si todas suas partes, não pode ser vista, então, como um simples agregado de elementos. Essa união ou composição singular, por ser feita de relações (diferenças - distinções entre movimentos -, passagens, transições) constitui ela própria uma relação (certa ratio ou proporção de movimento e repouso) que se comunica, por sua vez, com outras relações (outros corpos), compondo outros indivíduos diversamente complexos. O corpo do homem, desta sorte, está conformado por muitíssimos indivíduos fluídos, moles e duros, de natureza diferente, cada um dos quais é muito complexo; indivíduos que são afetados de muitíssimas maneiras pelos corpos

\footnotetext{
${ }^{13}$ SPINOZA, B., Correspondência, op.cit, p. 236.

${ }^{14} \mathrm{E}$, II, lema 1 da "pequena física".

${ }^{15} \mathrm{E}, \mathrm{II}$, axioma 2 da "pequena física" (definição de corpo composto).
} 
exteriores, que mantêm com o indivíduo como um todo um intercâmbio permanente (em virtude do qual o próprio corpo pode regenerar-se e conservar a proporção - a relação ou ratio - que caracteriza sua constituição). A maneira em que se dá essa convergência em totalidades articuladas, e a maneira em que a perspectiva varia ao considerá-las, é considerada por Spinoza quando diz que

\begin{abstract}
se supusermos que não há qualquer causa exterior ao sangue que lhe comunique novos movimentos, e que não existe tampouco nem espaço nem corpo algum fora do sangue aos quais as partículas sangüíneas pudessem transferir seus movimentos, é certo então que o sangue sempre permaneceria no seu estado e suas partículas não sofreriam qualquer variação, exceto as que podem ser concebidas a partir da natureza do sangue (...), nesse caso, o sangue sempre deveria ser considerado como um todo e não como uma parte. Mas como se dão muitíssimas outras causas que modificam, de algum modo, as leis da natureza do sangue e, por sua vez, são modificadas por estas, surgem no sangue outros movimentos e outras variações, que têm sua razão de ser não só no movimento mútuo entre as partes, mas também no movimento entre o sangue e as causas externas." 16
\end{abstract}

É por uma estrita questão de perspectiva (de perspectiva objetiva, pois igual que antes, no caso das figuras, não se trata de um problema de percepção "subjetiva") que Spinoza pode dizer que, enquanto concordam entre si, as partes convergem na composição de um indivíduo, mas enquanto discrepam ou se opõem, cada parte forma em nossa mente uma idéia distinta das demais - o que nos leva a considerá-la como um todo e não como uma parte. Assim, por uma questão de perspectiva, um vermezinho que vivesse dentro do sangue veria as partículas como indivíduos separados constituintes desse fluido que seria, para ele, como o ar que nós respiramos. Só uma "visão" mais abrangente poderia reconhecer que essas partículas nada são separadamente, e que respondem às exigências de ajuste mútuo que a natureza do sangue e suas leis de composição lhes impõe. Mas, ao mesmo

${ }^{16}$ SPINOZA, B., Correspondência, op.cit., pp. 236-237. 
tempo, supor que essas leis do sangue funcionam de maneira pura, constituiria deste modo outra operação de abstração que isolaria o sangue das relações com as outras coisas que "modificam as leis de sua natureza", produzindo nela movimentos e variações procedentes, assim, não do movimento de suas partes, mas, justamente, dessas causas externas. Desta sorte, o "movimento mútuo entre as partes" de uma coisa e "o movimento entre [essa coisa] e as causas externas" estão tão intimamente conectados, que "totalizar" no sentido de considerar as coisas como se fossem figuras opostas (ou "partes totais") é desnaturalizá-las. Por isso, podemos dizer que com este tipo de exemplos Spinoza se refere à natureza absolutamente relacional da existência, o que faz que das noções de parte e de todo, num sentido preciso, "entes de razão".

Podemos e devemos conceber todos os corpos da Natureza da mesma maneira como fizemos com o sangue (...) posto que todos eles estão rodeados por outros e se determinam mutuamente a existir e a operar de uma forma certa e determinada, de sorte que, ao mesmo tempo, mantenha-se sempre constante no conjunto, quer dizer, em todo o universo, a mesma proporção entre o movimento e o repouso. De onde se segue que todo corpo, assim que esteja modificado de algum jeito, deve ser considerado como uma parte de todo o universo, e deve estar acorde com seu todo e em conexão com outros corpos. E como a natureza do universo não é limitada como a do sangue, mas é absolutamente infinita, suas partes são moduladas de infinitas maneiras e estão submetidas por essa potência infinita a infinitas variações. ${ }^{17}$

As partes da natureza - e entre elas, o corpo humano - se determinam mutuamente a existir e a operar e, nesse sentido, coexistem numa afetação recíproca que faz delas partes sempre modificadas de uma ou de outra maneira. Cada corpo, então, enquanto existe atualmente, está de acordo com as outras partes e com o todo (pois, de fato, só nesse sentido pode dizer-se que existe). O caráter ilimitado do "todo" do universo - a natureza absolutamente infinita -, não nos habilita para fazê-lo objeto da abstração

17 Ibidem. 
que o restringe a uma "interioridade" de cujo "exterior" o separamos (por isso, a ilustração dos círculos podia servir para fazer referência à existência das coisas finitas, mas não à existência infinita). A natureza não tem exterior, mas, por isso mesmo, tampouco tem interior. E nesse sentido, não há nem ordem nem simetria numa natureza de poder infinito que "modula suas partes de mil maneiras”.

\section{A natureza conflitual da existência (ou a complexidade da determinação)}

Se as partes da natureza são infinitamente determinadas e moduladas "de mil maneiras" distintas em virtude do jogo recíproco das leis que constituem a multiplicidade de naturezas que compõem a natureza absoluta, elas mesmas são, enquanto "partes desse todo", graus singulares de uma potência produtiva que explica suas existências e suas próprias capacidades de ação e operação. Neste sentido, são intensidades expressivas de uma potência natural, pela qual, como dissemos, identificam-se com sua força de afirmar sua essência e com a própria realidade concreta de seus atos. Assim, enquanto se esforçam por permanecer na existência, as coisas finitas (sejam corpos, sejam modos do pensamento), enfrentam-se e coexistem conflitivamente, e também se articulam e conformam configurações mais potentes quando conseguem confluir (confluência que, entretanto, não é uma lei). "Ser finito, em verdade, é negação parcial” (E I, P8, esc. 1) da existência de uma natureza qualquer.

Que ser finito seja uma negação parcial significa que há algo que se afirma e algo que se nega em simultâneo; concretamente, a negação compete ao caráter finito das coisas singulares, enquanto que a afirmação se refere ao fato de que se trata de entes realmente existentes, ou seja, modos de uma substância infinita que só é em suas modificações. Ou, dito de outra forma, a negação remete à inelutabilidade da determinação externa que afeta às coisas singulares, e sua parcialidade ao fato de que tal negação não é absoluta, mas está em necessária conexão com a determinação interna - o que faz dos entes finitos uma relação entre essas duas direções divergentes da interação, e da vida de cada um deles uma mistura de ações e padecimentos. Como ressalta bem Rousset, a realidade da determinação externa não implica nem que não haja determinação interna em uma coisa finita, nem que não haja negações também internas em uma coisa finita, "pois um ser finito, na relatividade de 
sua definição e de sua composição, é tributário da contrariedade de determinações extrínsecas que o constituem" ${ }^{18}$.

Desta maneira, o conflito não é unicamente exterior, e esta afirmação vale não só para uma configuração ampla, mas é válida em relação à constituição própria dos indivíduos finitos. Pois não é possível separar, se devemos ser rigorosos, um âmbito de interioridade definido pela atividade, e outro âmbito de padecimentos, que seria algo assim como sua borda (como a circunferência do círculo), submetida aos embates exteriores; como se houvesse uma realidade profunda das coisas - feita da força ativa e positiva da perseverança no ser - e uma superfície dessas mesmas coisas, constituída de roçamentos e de um afetar-se recíproco inevitável devido à coexistência espaço-temporal dos singulares. "Interior" e "exterior" estão profundamente imbricados, de tal maneira que todo "interior" está constituído de, e atravessado pela exterioridade; por isso, a determinação não é só externa, mas define também uma disposição interna, e tampouco o limite é só exterior (e nesse sentido, padecido) mas determina atualmente certas capacidades de ação; e, de igual forma, a oposição, a contrariedade e a negação não pertencem unicamente ao "mundo externo", pois enquanto esse mundo constitui necessariamente o ser de cada coisa singular como um "ser em relação", todo indivíduo vive "internamente" esses conflitos como oscilações, tensões e ambivalências que fazem de sua existência uma batalha e uma luta, num sentido cabal e não restringido. "As paixões não são referidas à mente senão enquanto tem algo que envolve negação, ou seja, enquanto considerada como parte da natureza, que não pode ser clara e distintamente percebida por si, sem as outras" (E III, P 3, esc.). A mente "tem algo que envolve negação" enfatizemos - que deriva dela ser necessariamente uma parte da natureza, que não pode ser isolada do contexto relacional no qual ela é e que a constitui.

Em virtude da afetação recíproca que se dá entre as coisas existentes, cada corpo está efetivamente misturado com os outros corpos - envolvendo toda afecção não só a natureza do corpo afetado, mas também a natureza do corpo que o afeta. A mente humana conhece (e desconhece) seu corpo - o corpo de que é idéia - enquanto percebe suas afecções, quer dizer, enquanto ela mesma, como idéia complexa, está constituída pelas idéias das afecções do

18 ROUSSET, B., "Regarde spinoziste sur la lecture hegelianne du spinozisme", em L'immanence et le salut. Regardes spinozistes, Paris, Kimé, 2000, p. 21. 
corpo. Dessa sorte, a mente também se conhece (e se desconhece) a si mesma, enquanto, como idéia de si (idéia da idéia que ela é enquanto idéia de um corpo existente em ato) contém as idéias das afecções. É dentro dessas condições que uma essência ou conatus se afirma. $\mathrm{O}$ esforço com que cada coisa singular tenta perseverar em seu ser (esforço que define sua essência atual) é um esforço sempre e necessariamente determinado, sendo as afecções do corpo e as idéias dessas afecções as condições da afirmação desse único conatus que corpo e alma exprimem e efetuam.

$\mathrm{O}$ conatus ou apetite constitui a essência do homem enquanto determinada a fazer algo que serve a sua própria conservação (assim como o apetite é a essência do cavalo enquanto determinada a fazer algo que serve à própria conservação do cavalo; e também seria a essência de um círculo, se o considerássemos como uma coisa natural, seu apetite ou impulso determinado a fazer com que persista o movimento que o define: a rotação de um segmento de reta em torno de um dos seus extremos concebido como fixo). Mas o apetite do homem em particular é o desejo, isto é, "o apetite quando dele se tem consciência” (E III, P9, esc.); ou seja que o homem, além de esforçar-se como todas as coisas naturais em perseverar em seu ser, percebe, quer dizer, é ciente desse esforço. O desejo, tal como Spinoza o define (na E III, Definições dos Afetos, $\mathrm{n}^{\circ}$ 1), é, destarte, “a própria essência do homem enquanto é concebida determinada a fazer algo por uma dada afecção sua qualquer", e nesta definição está fundamentalmente presente a imbricação entre essência e determinação que ressaltávamos, assim como a impossibilidade de separar um interior essencial ou ativo de um exterior que só se articularia, pretensamente, com a passividade. A explicação spinozana desta definição é precisa:

Poderia ter dito que o Desejo é a própria essência do homem enquanto é concebida determinada a fazer algo, mas desta definição não seguiria que a Mente [que não se conhece a si mesma senão enquanto percebe as idéias das afecções do corpo - E II, P23] pode ser cônscia de seu Desejo, ou seja, de seu apetite. Então, para que eu envolvesse a causa dessa consciência, foi necessário acrescentar enquanto é concebida determinada a fazer algo por uma dada afecção sua qualquer. Pois por afecção da essência humana entendemos uma constituição qualquer desta mesma essência. 
A essência sempre é uma essência "enquanto determinada" - e simultaneamente, determinada a fazer (agir) algo para conservar sua própria constituição, e determinada por uma dada constituição sua, isto é, "por uma dada afecção sua qualquer”. A afirmação de uma essência é incindível da afirmação da própria constituição - que incorpora a natureza dos corpos exteriores que se "misturam" com ela, em virtude de afecções de todo tipo. Nenhuma profundeza essencial, então, que possa abstrair-se ou supor-se protegida das vicissitudes "exteriores":

Portanto - conclui Spinoza - entendo aqui pelo nome de Desejo quaisquer esforços, ímpetos, apetites e volições de um homem que, segundo a variável constituição do mesmo homem, são variáveis e não raro tão opostos uns aos outros que ele é arrastado de diversas maneiras e não sabe para onde voltar-se.

A essência permanentemente variável de cada homem está constituída, então, por esses esforços, ímpetos, apetites e volições, em geral "tão opostos uns aos outros”, que se torna impossível associá-la com uma límpida e calma identidade continuamente afirmada. A essência do homem é o desejo, e isso faz de cada essência humana singular algo definido necessariamente por sua abertura para os outros homens e o resto das coisas que fazem o mundo. E por isso, um filósofo como Leibniz foi capaz de insistir uma e outra vez frente àqueles que queriam associá-lo com o spinozismo -, em que de forma alguma é possível confundir as mônadas (sem portas e sem janelas) com os indivíduos tal como Spinoza os concebe, que não guardam dentro de si o principio de sua ação e que dependem necessariamente dos outros indivíduos com os quais estão em relações que são, para cada um, constitutivas, e suscetíveis de ser também (graças à composição de esforços convergentes) constituintes de novos tipos e formas de individualidades complexas. 


\section{REFERÊNCIAS}

ALTHUSSER, L. et al. Lire le Capital. Paris: Maspero, 1968.

BALIBAR, E. Spinoza, Il transindividuale. Milano: Edizioni Ghibli, 2002.

DELEUZE, G. Spinoza et le probleme de l'expression. Paris: Minuit, 1968. . Spinoza: Filosofia Práctica. Barcelona: Tusquets, 2001.

- En medio de Spinoza. Buenos Aires: Cactus, 2003. Cursos sobre Espinosa proferidos entre 1978-81, também publicados no site: www.webdeleuze.com HEGEL, G.W.F, Lecciones sobre la historia de la filosofia. México: Fondo de Cultura Económica, 1979.

ROUSSET, B. "Regarde spinoziste sur la lecture hegelianne du spinozisme", In : L'immanence et le salut. Regardes spinozistes. Paris: Kimé, 2000.

SPINOZA, B. "Correspondência”, Os pensadores. São Paulo: Abril Cultural, 1979 Ética, Belo Horizonte: Autêntica Editora, 2007. 